\title{
Erratum to: Study the Sensitivity of Solid Lubricating Additives to Attapulgite Clay Base Grease
}

\author{
Zeyun Wang $\cdot$ Yanqiu Xia $\cdot$ Zhilu Liu
}

Published online: 31 March 2011

(C) Springer Science+Business Media, LLC 2011

\section{Erratum to: Tribol Lett}

DOI 10.1007/s11249-011-9754-1

The original version of this article unfortunately contained three mistakes. The captions of Figures 6,7 and 8 were incorrect. The corrected captions are given below.

Fig. 6 Friction coefficient as a function of time with lubrication of the base grease containing $\mathrm{MoS}_{2}$ or graphite/ $\mathrm{MoS}_{2}(800 \mathrm{~N}$ and $30 \mathrm{~Hz})$

The online version of the original article can be found under doi:10.1007/s11249-011-9754-1.

Z. Wang · Y. Xia $(\bowtie) \cdot$ Z. Liu

State Key Laboratory of Solid Lubrication, Lanzhou Institute of Chemical Physics, Chinese Academy of Sciences, 18 Tianshui Zhong Road, Lanzhou 730000, China

e-mail: xiayq@licp.cas.cn

\section{Z. Wang}

Graduate School of Chinese Academy of Sciences, Beijing

100039, People's Republic of China

Fig. 7 A comparison of the friction coefficient and wear rate as functions of sliding frequency for the attapulgite clay base grease containing $5 \mathrm{wt} \% \mathrm{MoS}_{2}$ and the bentone base grease containing $5 \mathrm{wt} \% \mathrm{MoS}_{2}$

Fig. 8 Friction coefficient as a function of time with lubrication of the base grease containing different additives, respectively $(200 \mathrm{~N}$ and $40 \mathrm{~Hz}$ ) 